\title{
Study on the Characteristics and the Development Vein of Oroqen Dance Culture*
}

\author{
Rui Zhang \\ School of Music \\ Heihe University \\ Heihe, China
}

\author{
Weibo Dang \\ School of Music \\ Heihe University \\ Heihe, China
}

\begin{abstract}
In early days, the development of Oroqen dance is decided by the change of the Oroqen people's life. It proves that the Oroqen dance is originated from and is an epitome of the Oroqen people's life. As the development of their production, Oroqen dance develops gradually into a unique folk dance. It appeared and spread among the people. With distinct style and lively rhythm, the dance becomes very popular. It reflects the working, struggle, life of Oroqen people. It is, vivid, cheerful and plain, an important aspect of their traditional culture.
\end{abstract}

\section{Keywords-Oroqne; dance; development}

\section{INTRODUCTION}

Oroqen is one of Chinese minority nationalities with small population. They live by hunting. Since remote antiquity, hunting had been their main source of income until the foundation of People's Republic of China. Through their production and life during long time, Oroqen people created their special songs and dances. The feature is dancing by singing.

\section{OROQEN PRIMITIVE DANCE VARIETIES AND STYLES}

Oroqen dance is considered as a kind of hunting culture. Closely related to hunting during its creation, it keeps some primitive styles and features obviously. Oroqen dance is usually accompanied by singing. Most movements derive from everyday life. The content which the dance expresses is also about everyday life. Under the influence of the environment, the dance includes mainly the imitation of the animal positions as well as songs and dances for self-entertainment. The dancers cheer up in correspondence with the rhythm. The lyrics, with only a few words though, are very rhythmic and catchy. So, these songs are very popular among the Oroqen people. Oroqen has its own language, but no characters. Its language belongs to the Tungusic Branch of Altaic language family. The people believe in primitive religions which worship the nature, the totems or the ancestors, etc. In Oroqen language, people call dance Lu Ri Ge Ren. The Oroqen dance can be classified into four categories: entertainment, labors, rituals and religions. The dances in all these categories start from slow movements, accelerate gradually and finally end

*Key Research Project of Heihe University; Russian Far East Evenki Music Research, Source: Heihe University Far East Think Tank Project, Project No.: 17YDZKCJC04. with intense actions. The performance is not accompanied by the instruments, but with the lyrics and songs, which is dancing by singing. Basic dance steps include fighters' dragging steps, etc. The lining words appear often in the dance music, such as Jiehui Jiehui, Ehu Dehu, etc. There are also some rhythmic calls, such as Zhe Hei Zhe, Jia Hei Jia, etc.

Fighting Bear Dance is possessed by all the Oroqen. They consider themselves very close with the bears. They even believe that bears are their ancestors. Thus, they worship bears. Before they eat the bear they capture, they must go through some rites. This is the origin of the Fighting Bear Dance. This dance is performed by three people. Men or women, young or old, all the people of Wulileng sit around the bonfire, taking meat and drinking wines, singing and dancing. The dance is composed of the imitation of animals' cries and movements. At the beginning, two dancers crouch face to face. The upper bodies bend forward. The hands press on the knees. Glaring at each other, the two dancers shouted Hamo Hamo, stomping, heads turning left and right, shoulders moving back and forth powerfully. Then, the cries are accelerated and the movements range is enlarged. The dancers stomp more and more powerfully. During the climax, the two dancers approach shoulder by shoulder to express the stubbornness. When the two people are locked in this battle, another dancer intervenes and tangles together with the two dancers, which pushes the dance into a new climax. The dance will not stop until all the three dancers are out of breath and one of them is defeated.

Ehulan, Dehulan is named after the lining words of the song. It shows the workings and the joys of the Oroqen women. The number of the dancers is unlimited. In each group of two face-to-face, one should go forward while another one should go backward. They dance in circle. Meanwhile, they clap their own hands or the other dancer's hands. Sometimes, they put up their hands over their heads and then rotate at the same time. Sometimes, clapping each other's hands, they will do some movements like carrying the preys or water, picking up fruits, or dressing up, etc. Accompanied by the songs, the dancers in tacit agreement perform in a cheerful ambiance with dancers. Qia Mu Qiao E Ri De Ri is also known as Qun Qiu Nen which means the hazel grouse. It is a game dance. The number of dancers is unlimited. But the dancers are mainly children. The dancers stand in a row, crouching with hands on the knees. After given the order, the dancers jump forward like hazel grouses while spectators keep on saying some encouraging and 
teasing words like tongue-twisters. The one that jumps to the destination first wins.

Yi He Na Ren is a ritual dance with strong religious colors. It is performed in the clan meeting every three years. Eleven dancers in one group, ten people make a circle and the other one stands in the middle. According to the rules, it is the prestigious Shaman or old man who stands in the middle because this meeting as a memorial ceremony for the clan ancestors must be guided by him. Every movement must conform to the rules. Even little mistakes are not tolerated. At the beginning, all the dancers, in the center and the circle, jump squats. Then, they stand up, hands in hands, and rotate by jumping in clockwise. The ambiance is very serious at the beginning, because the dance is aimed at the sacrifice for the ancestors.

\section{The OROQEN PRIMITIVE DANCES AND THE LIFE}

Nowadays, the Oroqen are still keeping a Hanbai dance. There is a beautiful story for this dance. There was a minority family living in the forest on the border of Heilongjiang Province. There were two aged parents, a son, a daughter in law and a grandson. One day, the son went out to hunt and did not come back after a few days. The whole family felt very upset. Then, they climbed up to the top of the mountain, looked out and shouted AHan-bai, Ahan-bai. They wished that the son could come back as early as possible. Later, they made a campfire in their courtyard and shouted the name of the son again at the mountain top. Suddenly, the grandson saw a figure in the distance. They recognized that it was just the Ahanbai who left home for many days. The whole family, so excited, just hopped and skipped. The grandmother dragged and beat the leather bags to carry the potherbs forcefully. The whole family overlooked with their hands up and shouted the name, Ahanbai, Ahanbai. Ahanbai jumped off the horse happily and danced with his family around the fire. Ahanbai dance was created in this situation. The Ahanbai dance spread up to now includes the movements such as hopping with hands at the forehead accompanied by drum beating by hands, etc. From this old story, we can find out that this dance originated from hunting and fishing is a rhythmed primitive dance accompanied by simple shouting-style tunes in early days.

In hunting period, the Oroqen people wandered in the broad mountains and forests. They have not only broad mind, but also personalities like mountains, which endow their traditional music with unique characteristics. On expressiveness, the Oroqen folk song is sonorous and vigorous, mellow and resounding with melodies full of ups and downs. Fighting Bear Dance is an Oroqen traditional dance. The Oroqen people cannot call the bears by the name directly. The bear should be called Weiya which means grandfather or Taitie, that is grandmother. In some areas, the bear is called Amaha which means uncle. In the past, there is the habit of bear hunting. Even the hunters beat a bear to death, a whole set of funeral rites.

The Oroqen people changed their agricultural and hunting styles with the change of their living and production during the transformation from hunting to agricultural period. The transformation is obvious but subtle, fresh but not away from the traditional forms. First, they continued their styles of the traditional music in hunting period. However, the new folk songs possess strong flavor of the times. Moreover, some new themes appeared, such as the happy new life after going down the mountain and the memory on the mountains, forests, rivers and old hunting life. Meanwhile, the music style changed too. Jian Da Wen becomes more variable with the influence of the folk music of other nations nearby. Second, in hunting and agricultural life, because Lu Ri Ge developed into the dance and song only for entertainment, its function of protection against the cold existed no more. People perform Lu Ri Ge, the imitation of animals' cries and some scenes in hunting and everyday life, only in festivals, parties and outings to cheer up. As they live down the mountains longer and longer, mandarin becomes their main language for internal and external communication. Thus, the ability of Mo Su Kun singers nowadays to master their traditional language weakened. Finally, Mo Su Kun gradually disappeared with cultural communication more and more frequent and living standard higher and higher after the Oroqen people settled down.

The Oroqen people work very hard and seriously out of long-term hunting life in the mountains and forests even in the rain and wind. Moreover, the Oroqen people act on what they say. They look down upon those who go back on their words. There is a saying among them that the incompetent hunters always complain about their shotguns; the unambitious men always blame everyone and everything but themselves. These words show their personality of keeping promises. During the research, many Oroqen members mentioned that their nation is very good at singing and dancing and their ancestors left variable dances and songs through many years. Under this circumstance, we need talents to development our folk dances into a complete system like others. Some Oroqen folk artists worry about the slow development of their culture so much that they cried during the interview. This indicates their selfesteem and sense of responsibility for their nation.

\section{The INFluence OF LIFESTYLE CHANGE ON THE SONGS AND DANCES}

As the only remaining hunting nation in China, the Oroqen is regarded as the living fossil of the hunting and fishing nationality in the Northern Hemisphere. Their special forest culture formed through long-term hunting. Mr. Meng, the Deputy to the 11th National People's Congress, affirms that the development and integration of Oroqen traditional culture can provide an important reference for the research on the evolution of the hunting and fishing nationalities in the Northern Hemisphere. With the evolution of their production and life styles, the existing folk artists and intangible cultural inheritors are few in number and advanced in years while many young people are indifferent in their culture. As a result, the Oroqen folk culture is in danger of being lost. Thus, the protection is extremely urgent. In many regions, the minor festivals with folk songs and dances are taken as a means to attract investment. Cultural activities are often twisted by the capital. In this case, the traditional folk dances are often abused.

By the phenomena happening everywhere in China, we can find out that the folk dances in all regions are being destroyed 
on different levels. The styles of some dances are transformed. The national properties of some dances are alienated. These low-quality folk and primitive dances are identical in creative techniques and monotonous in performing form. They cannot guide us to find out our spiritual home. They can only provoke the consumers' esthetic fatigue. The consumers will feel cheated by these performances. Finally, folk dances will lose their original forms in the new ecological environment, which will hinder their healthy development. Thus, this is a very worrying situation.

\section{CONCLUSION}

The ancient dances are an important part of the Oroqen life. Since hundreds and thousands years, they express their emotion and expectations to their lives with songs and dances. They dance in honor of their gods and ancestors to express their reverence and memorial so as to encourage the living persons to cherish their lives. It should be highlighted that these ancient songs and dances are all attached to the Oroqen folk culture and rituals just like the soil on which they grow. In return, the dances which express the emotion by body language support these important customs and folk rites. People express their emotion and worship with dance and present their internal sense of identity to their national culture.

Nowadays, the key object of social spiritual civilization construction is to improve the cultural quality of the entire people. In fact, aesthetic education is one of the best methods. Thus, we can only keep the Oroqen culture completely when we protect those important folk customs and rituals well. Only when we respect the customs, can we maintain and renew the vigor of the folk dance.

\section{REFERENCES}

[1] Li Xiangchen, The Oroqen Folk Songs [J]. Chinese Music, 1984(03).

[2] Tian Liantao, Chinese Minority Music [M]. Central University for Nationalities Press, 2001..

[3] Qiu Pu, The Development of Oroqen Society [M]. Shanghai People's Publishing House, 1980.

[4] Zhao Fuxing, Brief Introduction to the Oroqen [J]. Inner Mongolia Social Sciences, 1981(01).

[5] Feng Guangyu, Wang Guiqin, Evenks, Oroqen and Daur Folk Music from Modern Vision [J]. Academic Journal of Art College of Inner Mongolia University, 2006(01). 